\title{
Heat transfer enhancement in the oscillating turbulent flow of a pulse combustor tail pipe
}

\author{
JOHN E. DEC, $\dagger$ JAY O. KELLER $\ddagger$ and VEDAT S. ARPACI $\dagger$ \\ $\dagger$ University ur Michigan, Ann Arbor, MI 48109, U.S.A. \\ + Combustion Research Facility, Sandia National Laboratories, Livermore. CA 94551-0969, U.S.A.
}

(Receined 13 March 1990 and in final form 19 March 1991)

\begin{abstract}
Heat transfer rates in pulse combustor tail pipes and in other reversing, oscillating, turbulent flows have been found to be much higher than those of steady turbulent flow. To elucidate the mechanisms of the enhancement, the temperature and velocity fields, measured with two-line atomic fluorescence (TLAF) and laser Doppler velocimetry (LDV), respectively, are compared. Time-resolved wall heat fluxes and Nusselt numbers are also presented and discussed. Possible causes for the heat transfer enhancement in oscillating flows are reviewed and discussed in view of the data presented in this paper and the recent literature.
\end{abstract}

\section{INTRODUCTION}

Convectrve heat transfer rates from some oscillating flows can be much higher than those of steady turbulent flow at the same mean Reynolds number. These high heat transfer rates can be utilized to create lowcost, compact heat exchangers, while in other situations the effect is undesirable and can result in overheating and mechanical damage. Pulse combustor tail pipe heat transfer, and the heat exchangers of Stirling engines, are examples of devices in which the increased heat transfer from flow oscillation is used advantageously. The undesirable effect can occur in internal combustion and rocket engines, where acoustic resonances excited by knock and combustion instabilities, respectively, resuit in velocity oscillations, which sometimes cause engine damage or failure. In order to utilize this heat transfer effect or prevent it causing damage, it is important to understand which oscillating flows create heat transfer enhancements, and how the enhancement is related to various flow parameters. Also, understanding the behavior of the velocity and temperature fields during the flow oscillations can provide valuable information for oscillating-flow modeling and insight into the fundamental mechanisms responsible for the enhancement.

A review of the literature reveals that flow oscillations have been found to cause both increases and decreases in heat transfer rates. This apparent dichotomy may be resolved by careful examination of the individual works. Several studies have been performed in which the amplitude of the velocity oscillations was smaller than the mean velocity [1-5]. In these studies, the effect of the oscillations on the heat transfer was

\$Currently at Sandia National Laboratories, Combustion Research Facility, Livermore, CA $94551-0969$, U.S.A. small, with most researchers reporting a decrease in heat transfer, although some noticed no measurable effect and others a slight increase. Other studies have been performed on flows in which the oscillating velocity was large with respect to the mean velocity, thus creating periodic flow reversals [4-7]. In these studies, heat transfer increases of as much as a factor of 5 over steady flow have been reported. Two studies $[4,5]$ contain ciata for both flow regimes in the same experimental apparatus. These studies showed that velocity oscillations with amplitudes less than the mean decreased the heat transfer rate slightly [5], or had no measurable effect [4], but high amplitude oscillations (greater than the mean velocity) increased the rate of heat transfer significantly. From this evidence it may be concluded that, in order to get significant heat transfer enhancements over steady flow conditions, the oscillating velocity must be sufficiently large to cause periodic flow reversals.

For flows in which the velocity periodically reverses, at frequencies below about $100 \mathrm{~Hz}$, the trends in magnitude of the heat transfer enhancement with the various flow parameters are also found in the literature. The Nusselt number increases with increases in the amplitude of the velocity oscillations $[4,5,7]$, increases with the oscillation frequency for frequencies between 50 and $100 \mathrm{~Hz}$ [7], and decreases with increases in the mean flow rate for a given oscillation amplitude and frequency [5, 7]. These trends are generally consistent for all the available data, although the actual values vary between studies. Information on flows with higher-frequency oscillations is scant; however, two studies $[8,9]$ indicate that heat transfer increases do occur.

Creating flow oscillations of a magnitude sufficient to create heat transfer enhancement can require considerable work input; the advantages of increased heat transfer must be weighed against the cost of producing the oscillations. One method of minimizing 


\section{NOMENCLATURE}

$A$ cross-sectional area of the tail pipe

$B \quad$ used when $U$ and $T$ are shown on the same plot; $B$ may be either $U$ or $T$

$C_{p}$ constant pressure specific heat

$D \quad$ hydraulic diameter, equals the length of one side of the square pipe

$h$ heat transfer coefficient

$k$ thermal conductivity

$\mathrm{Nu} \quad$ Nusselt number, $h \mathrm{D} / k$

$P$ pressure

$P_{\text {RMS }}$ combustion chamber pressure, root mean square about the mean

$q$ heat flux

$R \quad$ hydraulic radius of the tail pipe

$\overline{R e} \quad$ time-averaged Reynolds number, based on $\bar{U}$ and $D$

$t$ time variable

$t_{\text {cycle }}$ period of a complete cycle

$t^{\prime}$ random gas temperature fluctuations, instantaneous value

$T$ gas temperature, instantaneous value, $T(t)=\bar{T}+T_{\text {oxi }}(t)+t^{\prime}(t)$

$\bar{T} \quad$ gas temperature time-averaged mean

$\langle T\rangle$ gas temperature, ensemble-averaged value, $\langle T\rangle(t)=\bar{T}+T_{\text {ox }}(t)$

$\left\langle T^{\prime}\right\rangle$ random gas temperature fluctuations, ensemble-averaged value, $\left\langle T^{\prime}\right\rangle(t)=$ $\sqrt{\left\langle\left(t^{\prime}\right)^{2}\right\rangle(t)}$

$T^{\prime} \quad$ random gas temperature fluctuations, time-average mean of $\left\langle T^{\prime}\right\rangle(t)$

$T_{\mathrm{B}} \quad$ bulk flow temperature

$T_{\text {core }}$ spatial average of the gas temperature in the core
$T_{\text {asc }} \quad$ gas temperature, oscillating component

$T_{\text {wall }} \quad$ wall temperaturc

$u^{\prime} \quad$ streamwise turbulence intensity, instantaneous value

$U$ streamwise velocity, instantaneous value, $U(t)=\bar{U}+U_{\mathrm{osi}}(t)+u^{\prime}(t)$

$\bar{U}$ streamwise velocity time-averaged mean

$\langle U\rangle$ streamwise velocity, ensemble-averaged value, $\langle U\rangle(t)=U+U_{\text {osc }}(t)$

$\left\langle U^{\prime}\right\rangle$ streamwise turbulence intensity, ensemble-averaged value, $\left\langle U^{\prime}\right\rangle(t)=$ $\sqrt{\left\langle\left(u^{\prime}\right)^{2}\right\rangle(t)}$

$U^{\prime}$ streamwise turbulence intensity, timeaveraged mean of ensemble-averaged values

$U_{\text {ose }} \quad$ streamwise velocity, oscillating component

$U_{x \mathrm{max}}$ streamwise velocity, oscillation amplitude, the maximum value of $U_{\text {ose }}$

$V$ transverse velocity

$X \quad$ spatial variable along the axis of the tail pipe; $X=0$ is the contraction-section tail pipe interface

$Y \quad$ vertical spatial variable normal to the tail pipe axis; $Y=0$ is at the wall

$Z$ horizontal spatial variable normal to the tail pipe axis: $Z=0$ is the tail pipe centerline.

Greek symbol

$\rho \quad$ gas density. the work input is to create the oscillations by establishing an acoustic resonance in the flow. However, the required work input is still greater than that of steady flow, since the skin friction is also increased by the oscillations [10]. Pulse combustion heating devices, which have large velocity oscillations in the tail pipe as a result of an acoustic resonance, are particularly well suited for utilizing this heat transfer enhancement. In these combustors, the acoustic resonance is driven by the combustion process itself, so there is no associated cost penalty. More complete discussions of pulse combustors, their applications, and research needs may be found in recent review articles [11-13].

This paper presents the results of a study performed in the oscillating flow of a pulse combustor tail pipe. $A$ description of the flow field and the experimental facility follow this introduction. Although the acoustic resonance and resulting velocity oscillations are driven by the periodic combustion process, the periodicity of the combustion has little other effect on the flow in the tail pipe. Temporally resolved measure- ments of the gas temperature near the end of the combustion chamber show that by the time the combustion products enter the tail pipe they are well mixed and at a steady temperature of about $1500 \mathrm{~K}$ [14]. Also, as seen below, the area change between the combustion chamber and tail pipe causes the magnitude of the oscillations to vary only slightly from tail pipe entrance to exit. Thus, the combustion chamber acts to supply steady temperature hot products to the tail pipe where the flow oscillates with periodic reversals in a slug-like fashion.

In order to better utilize and control the heat transfer enhancement created by flow oscillations, an understanding of the fundamental thermal and fluid mechanics is required. Recent studies by Dec and Keller [15] and Dec et al. [10] have respectively reported on the time-resolved temperature and velocity behavior in the reversing, oscillating, turbulent flow in the tail pipe of a pulse combustor. Although these studies have added considerably to the understanding of the mechanics of this type of flow, several aspects remain unreported. In this paper the velocity 


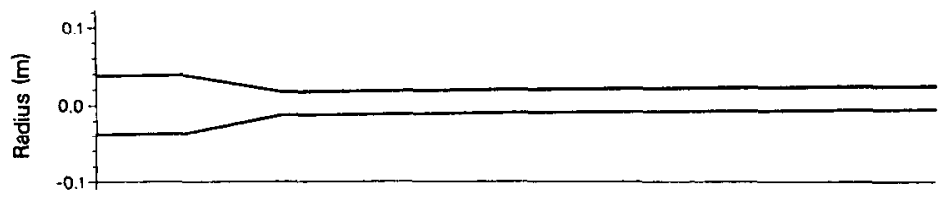

$\mathrm{x}$

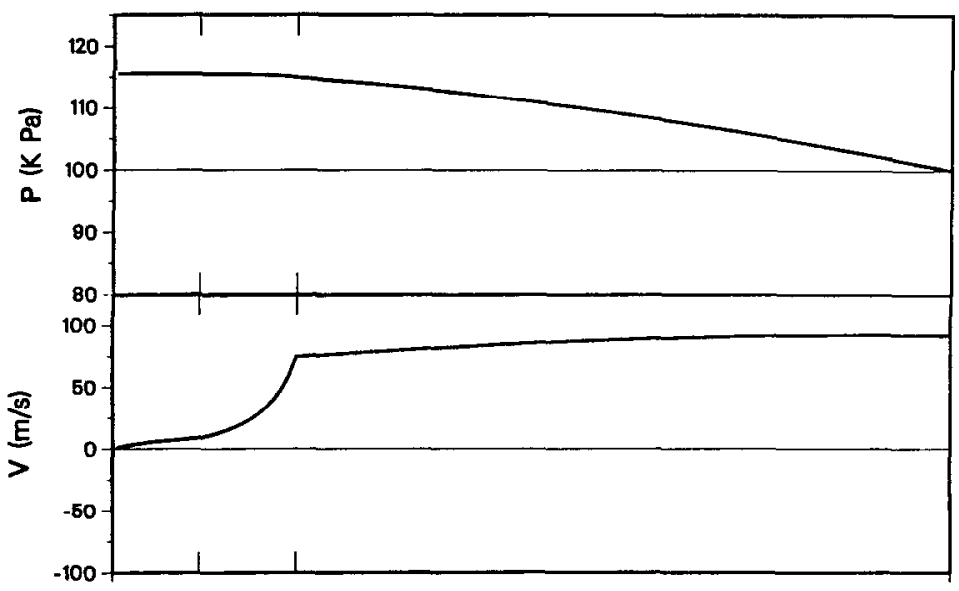

FIG. 1. Outline drawing of the pulse combustor and typical plots of the oscillating pressure and velocity distribution at times of maximum oscillation.

and temperature fields are compared, and the temporal behavior of the Nusselt number is determined by combining time-resolved heat flux data with that of the temperature and velocity fields. In addition, the possible mechanisms for the observed heat transfer enhancement in oscillating flows and their credibility in view of the recent data are discussed.

\section{FLOW FIELD DESCRIPTION}

For the combustor used in this study the acoustic resonance is roughly that of a quater-wave tube with variable area. An outline drawing of this pulse combustor and plots of the maximum oscillating pressure and velocity waves generated by the acoustic resonance are shown in Fig. 1. At the combustion chamber end are a pressure antinode and velocity node, while at the tail pipe exit are a pressure node (constant at atmospheric pressure) and velocity antinode. The acoustic resonance creates velocity oscillations superimposed on the mean flow of combustion products through the tail pipe. The amplitude of these velocity oscillations is greatest at the tail pipe exit and decreases sinusoidally toward the tail pipe entrance. However, because of the area change between the combustion chamber and tail pipe the velocity oscillations at the tail pipe entrance are only $20 \%$ less than those at the exit (see Fig. 1).

The combustion chamber pressure and tail pipe velocity oscillations for a typical operating condition are plotted in Fig. 2. These values are plotted against time normalized by the period of a complete cycle. Both waveforms are sinusoidal and are out-of-phase by approximately one quarter of a cycle. This is in agreement with acoustic theory for quarter-wave-tube resonance. In a resonant flow, the velocity oscillations are pressure driven, and the flow direction varies from being against the axial pressure gradient (adverse) to being with the axial pressure gradient (favorable) twice each cycle, as noted on the figure.

Linear acoustic wave equations predict that the amplitude of the velocity oscillations in the tail pipe

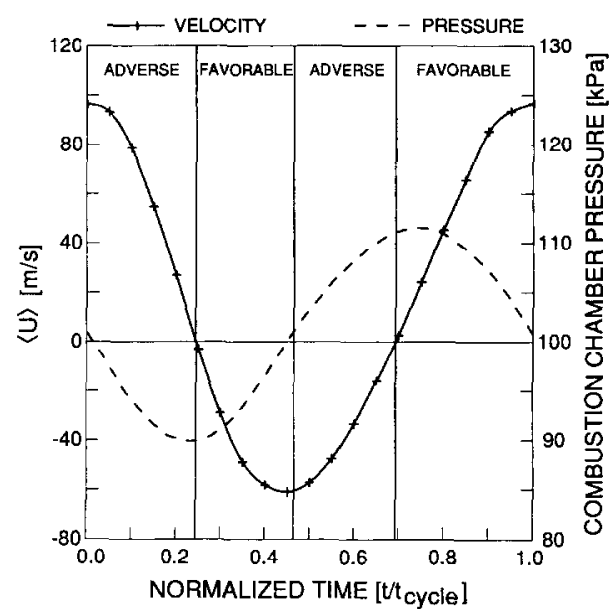

FIG. 2. Streamwise velocity and combustion chamber pressure during a combustor cycle. The velocity measurements were taken at the tail pipe centerline, $540 \mathrm{~mm}$ from the tail pipe entrance at a combustor frequency of $83 \mathrm{~Hz}$ and $P_{\mathrm{RMS}}-7.4 \mathrm{kPa}$. 'ADVERSE' and 'FAVORABLE' refer to direction of the axial pressure gradient with respect to the velocity. 
will be directly related to the amplitude of the combustion chamber pressure oscillations. Experimental measurements in the pulse combustor $[10,16]$ used in this study have shown that this relation generally holds. A good correspondence was found between the trends of the root mean square about the mean of the combustion chamber pressure $\left(P_{\mathrm{RMS}}\right)$ and the maximum value of the oscillating velocity in the tail pipe $\left(U_{\text {ow max }}\right)$. However, $P_{\mathrm{RMS}}$ was generally found to show a greater variation for a given change than did $U_{o x-\max }[10]$. In the present paper, the term pulsation amplitude refers to the oscillating velocity, which is the important parameter in the heat transfer enhancement. $P_{R M S}$ is used to indicate trends in the velocity oscillations and to compare the pulsation amplitude of various operating conditions.

\section{EXPERIMENTAL FACILITY AND DIAGNOSTICS}

Experimental facility

The pulse combustor used in this study was a 'Helmholtz' type with an external flapper valve. A schematic of this combustor with typical dimensions, is shown in Fig. 3. This combustor consists of an axisymmetric injection or 'mixing' chamber, and square cross-section combustion chamber, contraction section and tail pipe. Acoustic termination for the tail pipe was provided by a large-volume decoupling chamber. Reactants were premixed upstream of the flapper valve and injected on axis. Mean reactant mass flow rates were metered and controlled with sonic nockles. The reactants were pure methane and air at an equivalence ratio of 1.0 , and a variable fraction of nitrogen diluent, which was used to control the energy release rate as discussed below.

The tail pipe consisted of a coaxial square pyrex tube arrangement, as shown in Fig. 3. (A square crosssection was required to permit optical access for the laser diagnostics.) In this arrangement the inner tube, which was $30 \mathrm{~mm}$ square on the inside with a wall thickness of $4.75 \mathrm{~mm}$, formed the resonance tube for the pulse combustor and carried the combustion products. The outer tube was $51 \mathrm{~mm}$ square on the inside, providing a $5.75 \mathrm{~mm}$ wide channel between the tubes on all four sides. Cooling air flowed through this square annular space between the inner and outer tubes, entering at the decoupler end of the tail pipe and exiting at the contraction section end. This tube arrangement therefore formed a counterflowing heat exchanger. The tail pipe was constructed in a modular

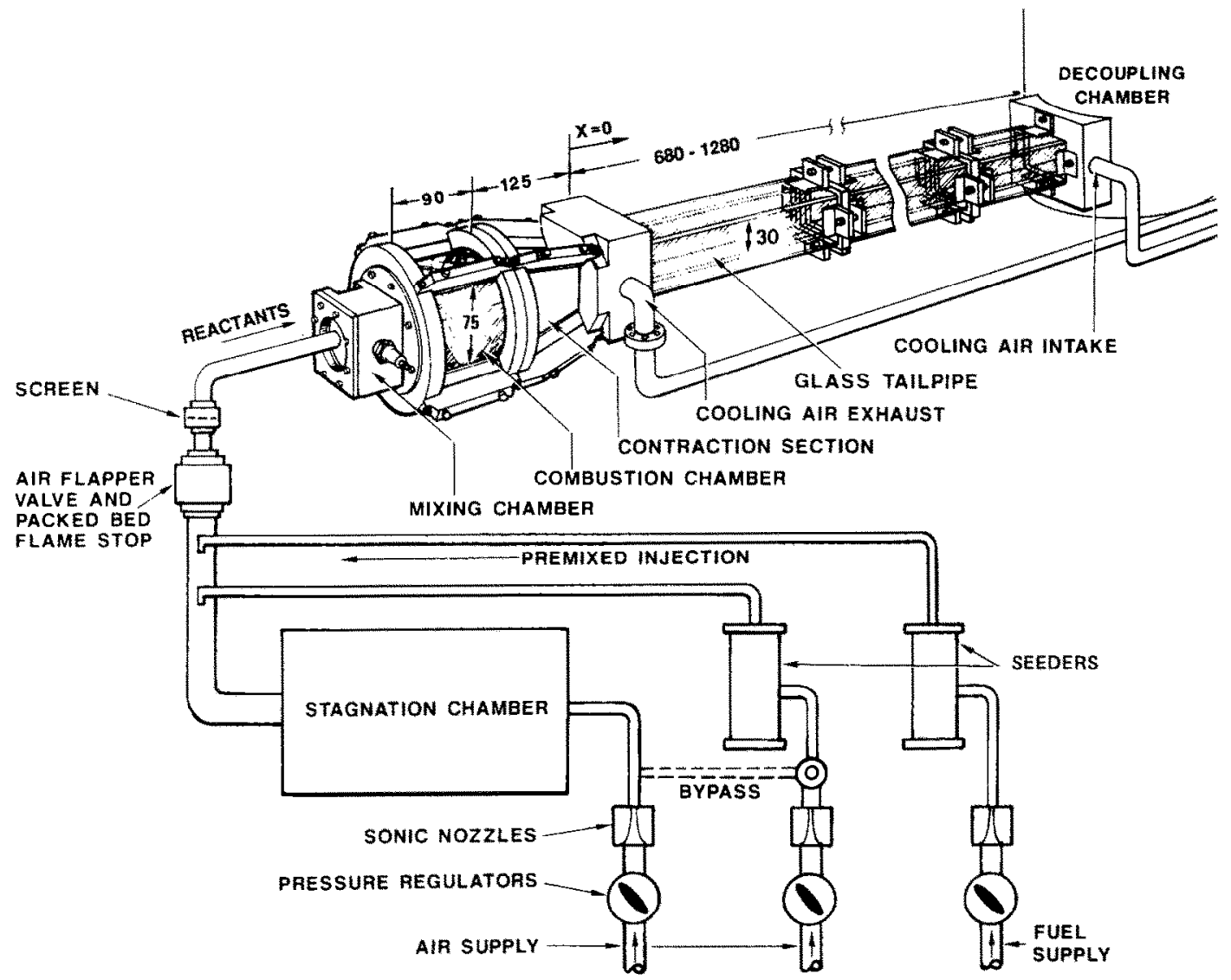

FIG. 3. Schematic of the pulse combustor facility, showing the variable length cooled tail pipe used in this study, All dimensions are in millimeters. 
fashion, allowing its length to bc varicd in $200 \mathrm{~mm}$ increments from 680 to $1280 \mathrm{~mm}$, to obtain operating frequencies from 101 to $67 \mathrm{~Hz}$, respectively. This modular construction also permitted the insertion of two special test sections at $200 \mathrm{~mm}$ increments. One test section had optical quality walls for laser diagnostic access, and the other was equipped to measure time-resolved wall temperatures and heat fluxes. The inner tubes of these two test sections were made of fused silica quartz rather than pyrex. The $17 \%$ difference in the thermal conductivities of these two materials produced only a negligible $2.5 \%$ difference in the overall heat transfer coefficient, which is dominated by the convective terms.

The following coordinate system was used in this study. $X$ is along the axis of the tail pipe with the origin at the interface between the contraction section and the tail pipe, as shown in Fig. 3. $Y$ is the vertical coordinate with its origin at the wall surface. $Z$ is the horizontal coordinate with its origin at the tail pipe centerline. All profiles presented are $Y$ profiles taken at $Z=0$. Measurements at the various $X$ positions, and $Y$ profiles, were obtained by moving the entire combustor, which was mounted on a three-dimensional translation stage. All times given for the cycleresolved data have been normalized by the period of a complete cycle.

\section{Pulse combustor control}

For this study the pulse combustor was operated over a range of frequencies and pulsation amplitudes. Combustor frequencies were varied by changing the natural resonance frequency of the combustor through variations in the tail pipe length and subsequent adjustment of the timing of the energy release rate. The timing of the energy release rate for this premixed system was controlled by the mixing rate of the reactants with the hot products and the chemical reaction rate. By adjusting these two processes, the energy release was optimally timed for each natural resonance frequency, providing a maximum pulsation amplitude. Pulsation amplitudes were then decreased from this maximum by detuning the timing of the energy release through the addition of various amounts of nitrogen diluent to the reactants. Adding nitrogen slowed down the chemical reaction rate, which delayed the energy release rate. This effect could be made sufficiently strong to stop the pulsations completely and achieve steady flow. A complete discussion of this methodology for controlling the pulse combustor may be found in Keller et al. [17, 18]. Bramlette [19] discusses jet mixing concepts in the pulse combustor. Although strongly pulsing and steady flow conditions were obtained, the combustor would not operate in a stable manner across a wide range of intermediate pulsation amplitudes. As a result, only a modest range of pulsation amplitudes could be studied.

\section{Diagnostics}

The diagnostics used in this study were pressure transducers, laser Doppler velocimetry (LDV), two- line atomic fluorescence (TLAF), and a thin-film thermocouple. Pressure transducers were used to obtain the combustor frequency and to measure the combustion chamber pressure. The combustion chamber pressure was also used to establish a synchronizing trigger for the cycle-resolved measurements. This trigger defined time zero of the combustor cycle and was selected to occur at the downwardgoing zero-crossing of the oscillating component of the combustion chamber pressure.

A two-color LDV system was used to make temporally and spatially resolved measurements of two components of the velocity. This LDV system permitted measurements of the streamwise $(U)$ and transverse $(V)$ velocity components to within $130 \mu \mathrm{m}$ and $2 \mathrm{~mm}$ of the wall, respectively. A complete discussion of the LDV systcm may be found in ref. [10].

Spatially resolved gas temperature measurements $(T)$ were made using TLAF. This point measurement technique utilizes two continuous-wave dye lasers tuned to pump two electronic transitions of indium seed atoms. The resulting fluorescence emissions are at different wavelengths from the incident lasers, thereby eliminating elastic scattering from the windows. Temperature is determined from the ratio of the two fluorescence intensities using Boltzmann statistics. A complete description of this diagnostic technique may be found in ref. [20]. In the current study, all data were taken at a rate of $2 \mathrm{kHz}$, which provided a sufficient period of integration to minimize shot noise. The system was calibrated by matching the temperature obtained with a thermocouple (corrected for radiation) to the mean temperature obtained with the TLAF system [20].

Wall surface temperatures were measured with a thin-film thermocouple, vacuum deposited on the exhaust gas side surface of the inner tube of the tail pipe. This thermocouple, made of pure platinum/pure rhodium, was $10 \mathrm{~nm}$ thick; hence, its effect on the heat flux and wall temperature was negligible. The time constant of this thermocouple was experimentally determined to be less than $100 \mu \mathrm{s}$, sufficiently fast to obtain cycle-resolved wall temperalures. A second thermocouple was imbedded in the wall directly below the thin film junction. In order to minimize the effect of this second thermocouple on the heat transfer, fine $(0.005$ in.) wire was used and the hole into which the thermocouple was inserted was filled with a quartz-based adhesive, which had nearly identical thermal properties to the surrounding wall. A micrometer was used to measure the thickness of the wall between the two thermocouple junctions. The cycle-resolved heat flux was obtained from these two thermocouple measurements by solving the transient conduction equation in the wall. A complete discussion of this technique is provided in the Appendix.

\section{Data acquisition and terminology}

In an oscillating turbulent flow, the instantaneous values of both velocity components ( $U$ and $V$ ) and 
the gas temperature $(T)$ are defined to be composed of three terms. The notation for representing these terms and the appropriate ensemble-averages are presented for the streamwise velocity, with the same notation applying to $V$ and $T$ :

$$
U(t)=\bar{U}+U_{\text {ois }}(t)+u^{\prime}(t)
$$

where $U(t)$ is the instantaneous value, $U$ is the longtime average mean, $U_{\text {osc }}(t)$ is the periodic or oscillating component caused by the acoustic resonance, and $u(t)$ is the instantaneous value of the random fluctuations or turbulence, which are superimposed on the periodic oscillation. An ensemble average of the velocity over many cycles yields

$$
\langle U\rangle(t)=\bar{U}+U_{\text {osc }}(t)
$$

where $\langle U\rangle(t)$, the ensemble-averaged value, is still a function of time, since it varies through the cycle. Since $\langle u\rangle(t)=0$, the ensemble-averaged intensity of the random or turbulent fluctuations is given the symbol $\left\langle U^{\prime}\right\rangle(t)$, which is defined as

$$
\left\langle U^{\prime}\right\rangle(t)=\sqrt{\left\langle\left(u^{\prime}\right)^{2}\right\rangle(t) .}
$$

In the above discussion, the functional dependence on time has been noted for clarity for all appropriate terms. Since $\langle U\rangle,\left\langle U^{\prime}\right\rangle$, and $U_{\text {osc }}$ are always functions of time through the cycle, the functional dependence will not be noted in the remainder of this paper. The maximum value of $U_{\mathrm{osc}}$ is the amplitude of the velocity oscillation and will be denoted by $U_{\text {ose } \cdots \text { max }}$.

The cycle-resolved measurements of the streamwisc velocity were determined by ensemble averaging the measurements over a minimum of 400 combustor cycles. The time delay of each velocity realization from the time-zero trigger was recorded and the data were sorted into appropriate time bins, based on their time of arrival. A probability distribution function (PDF) was then constructed for each time bin. The mean of each time-bin PDF is then $\langle U\rangle, \bar{U}$ was obtained by averaging $\langle U\rangle$ over the cycle, and $U_{\text {osc }}$ was obtained by subtracting $U$ from $\langle U\rangle$. Similarly, the standard deviation of each PDF provides $\left\langle U^{\prime}\right\rangle$. Cycle-to-cycle variation will be included in this measurement of the turbulent fluctuations; however, it is considered negligible, since turbulence intensities near time zero, close to the synchronizing trigger, are in good agreement with those late in the cycle. The time-averaged turbulence intensity, $\bar{U}^{\prime}$, was obtained by averaging $\left\langle U^{\prime}\right\rangle$ over the cycle. A detailed description of this ensemble-averaging technique may be found in Dec et al. [10].

Identical data acquisition and reduction procedures were used to obtain the various terms of the gas temperature. Cycle-resolved gas temperature measurements were also determined by ensemble averaging over a minimum of 400 combustor cycles.

\section{Measurement uncertainties and error corrections}

Because all of the measurements presented in this paper are ensemble-averaged over many combustor cycles, the effect of random errors on the ensembleaveraged mean data $(\langle U\rangle,\langle T\rangle$, heat flux, and Nusselt number) and the reported cycle-averages of these data ( $U$ and $T$ ) is insignificant ( $\ll 1 \%$ ). However, random errors can contribute to the ensemble-averaged intensity of the random fluctuations $\left(\left\langle U^{\prime}\right\rangle\right.$ and $\left.\left\langle T^{\prime}\right\rangle\right)$ and their cycle-averaged values $\left(\bar{U}^{\prime}\right.$ and $\left.T^{\prime}\right)$. For the LDV set-up used in this experiment [10], a typical uncertainty for an individual $U$-velocity realization was about $\pm 1 \%$ of $\bar{U}$ at the centerline. Assuming that this error is uncorrelated with the random velocity fluctuations the maximum error introduced in the values of $\overline{U^{\prime}}$ presented in this paper is $< \pm 0.7 \%$. The precision of each TLAF realization is shot-noise limited and is therefore a function of signal strength [20]. When signals are weak this error will artificially add to the measured value of $\left\langle T^{\prime}\right\rangle$. In this study, the signal intensity of each channel of the TLAF was also recorded and a shot-noise correction applied to $\left\langle T^{\prime}\right\rangle$, as discussed in ref. [15]. With this correction applied, the uncertainty of the $T^{\prime}$ values reported in Fig. 6 (which are calculated by averaging $\left\langle T^{\prime}\right\rangle$ over the cycle) is estimated to be $< \pm 1 \%$ for $Y / R>0.1$ and $< \pm 3 \%$ for $Y / R<0.1$.

In the pulse combustor tail pipe, the large temporal gradients of the streamwise velocity create a significant velocity variation across some time bins. This induces temporal gradient broadening and temporal seed biasing errors in the mean and standard deviation of the streamwise velocity PDFs, which may be corrected by the technique discussed in ref. [10]. $\Lambda 11$ values of $\langle U\rangle$ and $\left\langle U^{\prime}\right\rangle$ presented have been corrected for this error. Temporal broadening corrections were not required for the gas temperature, since gradients were much less than those of the velocity, and there is no seed biasing with TLAF. Calculations showed that spatial gradient broadening errors were generally small [10], and no corrections were made.

\section{DATA PRESENTATION AND DISCUSSION}

Most data to be presented were obtained at a typical combustor operating condition and axial location, which will be referred to as the base condition and base location. The base condition is a tail pipe length of $880 \mathrm{~mm}$, a frequency of $83 \mathrm{~Hz}$, a $P_{\mathrm{RMS}}$ of $7.4 \mathrm{kPA}$, and a mean flow Reynolds number (based on $\ddot{U}$ at the mean temperature) of 3750 . The base location is $X=540 \mathrm{~mm}$. Data were also taken at other conditions and locations and will be compared to those of the base condition and location.

\section{Review}

In an earlier work, Dec and Keller [15] have reported the temporal behavior of the temperature field in the oscillating flow in this pulse combustor tail pipe. They found that the main cyclic temperature fluctuations could be described by the first two harmonics of $\langle T\rangle$. Data from ref. [15] are reproduced 


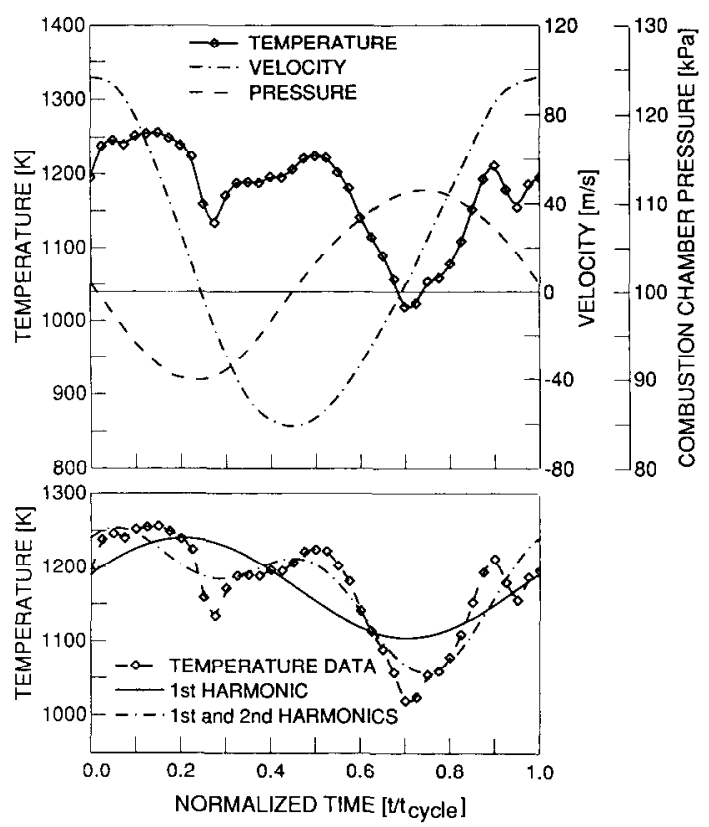

FIG. 4. A comparison of the cycle behavior of the gas temperature and velocity at the tail-pipe centerline, and the combustion chamber pressure, for the base operating condition and location. In the bottom plot are the temperature, its first harmonic, and sum of first and second harmonics from a Fourier series decomposition of the temperature fluctuations.

in Fig. 4, which shows the cyclic variation of the temperature and its harmonics at the tail pipe centerline at the case condition and location. (Also shown for reference are the velocity and combustion chamber pressure.) The first harmonic of $\langle T\rangle$ shows the fundamental temperature oscillation, which results from the oscillating velocity periodically convecting hot gases from the combustion-chamber end of that tail pipe and colder gases from the exit end past the probe location [15]. This results in the fundamental temperature oscillation lagging the phase of the velocity oscillation by one quarter of a cycle, as seen in Fig. 4. Superimposed on this oscillation are two distinct dips in the temperature at the times of the zero-velocity crossings. This phenomenon occurs twice each cycle, and was found to correlate with the second harmonic of the temperature [15]. The sum of the first and second harmonics of the temperature data may be seen to follow the major temperature fluctuations.

In this flow, there are significant differences between the cyclic behavior of the thermal $(\langle T\rangle)$ and fluid dynamic $(\langle U\rangle)$ boundary layers [10, 15]. Although the gas temperature at the centerline fluctuates more than $200 \mathrm{~K}$ through the cycle (Fig. 4), it is always much higher than the wall temperature, which remains at $640 \mathrm{~K}$, with a cyclic fluctuation of only $\pm 0.5 \mathrm{~K}$. The thermal boundary layer is well developed at all times during the cycle, although its thickness (temperature defect thickness) varies [15]. In contrast, the velocity reverses with respect to its wall value; oscillations at the centerline are from 95 to $-60 \mathrm{~m} \mathrm{~s}^{-1}$
(Figs. 2 and 4), while the wall velocity remains at zero. During the flow reversal, the fluid near the wall reverses earlier than that in the center or core region of the tail pipe. This results in a flow reversal through the $\langle U\rangle$ boundary layer at some times during the cycle, as discussed in ref. [10]. These large differences between the temperature and velocity fields, and the fact that the velocity oscillations are driven by an oscillating pressure gradient, show that neither the energy and momentum equations, nor their boundary conditions, are similar. Thus, the Reynolds analogy between momentum and energy or any heat transfer correlations based on it are not valid in this flow.

\section{Comparison of time-averaged thermal and velocity profiles}

Despite the differences in the temporal behavior of the $\langle U\rangle$ and $\langle T\rangle$ profiles, their cycle-averaged appearance is similar, as seen in Fig. 5. Shown are $\bar{U}$ and $\bar{T}$ profiles at the base location for the base $(83 \mathrm{~Hz})$ and $67 \mathrm{~Hz}$ operating conditions, appropriately normalized as noted in the figure. Both profiles have a nearly linear region near the wall and are fairly flat across the core region, as is typical of fully developed turbulent pipe flow.

There are, however, significant differences between the $\bar{T}$ and $\bar{U}$ profiles. In the core region $(Y / R>0.2)$, the $\bar{T}$ profiles have the trend of being flatter than those of $\bar{U}$, although there is more scatter in the temperature data, which manifests itself in the waviness of the lines, which are cubic spline fits to the data points. (This scatter is thought to be due to the TLAF system drifting slightly off calibration between the two data sets used to fit the curve.) The trend of a flatter temperature profile in the core implies that on the mean, the thermal mixing is greater than the momentum mixing. A more evident difference between the $\bar{U}$ and $T$ profiles is seen in the near wall region. The wall gradients of the $\bar{U}$ profiles for the two frequencies are

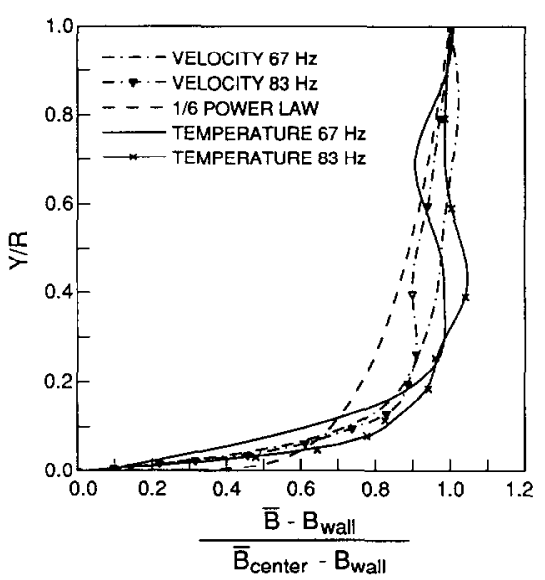

FIG. 5. Comparison of time-averaged velocity and temperature profiles at two frequencies. Also shown for reference is a $1 / 6$ power law curve, which represent steady flow at the same mean Reynolds number. In the label of the horizontal axis, $B$ may be either $U$ or $T$ 
virtually identical, in agreement with ref. [10], which found the wall shear stress to have no variation with frequency. In contrast, the wall gradients for the $\bar{T}$ profiles for the same two frequencies are significantly different. These wall gradient differences of the normalized $\bar{T}$ profiles are in agreement with a previous heat transfer study [7] in this flow which showed the Nusselt number to increase with frequency. The reasons for the differences between the $\bar{U}$ and $T$ behavior and their dissimilar response to frequency changes is not known; however, as noted above, the governing equations of momentum and energy, and their boundary conditions, are dissimilar in this flow.

Also shown in Fig. 5 is a curve for the $1 / 6$ power law, which provides a good approximation of the velocity profile in the corc region for steady (nonoscillating) turbulent duct flow at a Reynolds number of 4000 [21]. This curve can be considered typical of the thermal profile in steady turbulent flow as well, since the Reynolds analogy is known to hold in most steady pipe flows. Both the $\bar{U}$ and $\bar{T}$ profiles may be seen to be much flatter than this $1 / 6$ power law curve, in the core region, indicating a greater mean transport of momentum and thermal energy than would be expected for steady turbulent flow.

Time-averaged intensities of the random fluctuations of the velocity and temperature $\left(\overline{U^{\prime}}\right.$ and $\left.\overline{T^{\prime}}\right)$ are shown in Fig. 6, for the same two conditions as the data in Fig. 5. The $\bar{U}$ profiles rise sharply near the wall, then from $Y / R \approx 0.1$ to the centerline they are flat. The $\bar{T}$ profiles also rise sharply near the wall, but for $Y / R>0.1$ they decay gradually towards the centerline. This drop of $T^{\prime}$ in the core is thought to be due to the lack of thermal gradients in this region, since both random velocity fluctuations and fluids of

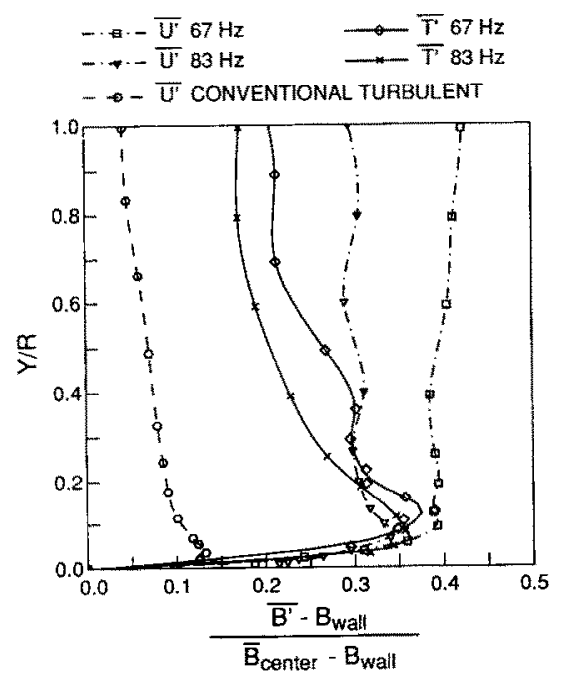

FIG. 6. Comparison of time-averaged streamwise turbulence intensity and random temperature fuctuation profles at two frequencies. Also shown for reference is a streamwise turbulence intensity profile for steady flow. This profile is the data of Reichardt as adapted from Schlichting [21]. In the label of the horizontal axis, $B$ may be either $U$ or $T$. different temperatures are necessary to create $\overline{T^{\prime}}$. Also shown are streamwise turbulence data from Reichardt, as adapted from Schlichting [21] for steady turbulent flow at a Reynolds number of 15000 in a large $(0.244 \times 1.0 \mathrm{~m})$ rectangular duct. The turbulence intensity in the pulse combustor tail pipe is much higher than that of the steady flow at Reynolds number more than three times higher. In Fig. 6 the intensities of both $\overline{U^{\prime}}$ and $\overline{T^{\prime}}$ are a little lower at $83 \mathrm{~Hz}$ than at $67 \mathrm{~Hz}$; however, comparisons of these profiles over the range of frequencies studied $(67-101 \mathrm{~Hz})$ showed no trend of either $\overline{U^{\prime}}$ or $\overline{T^{\prime}}$ with frequency. Complete discussions of the random temperature fluctuations and the turbulent velocity fuctuations may be found in refs. [15] and [10], respectively.

\section{Cycle-resolved Nusselt number}

A cycle-resolved Nusselt number shows the variation in the convective transport rate through the cycle. Determining the cycle-resolved Nusselt number requires a cycle-resolved measure of the heat transfer coefficient $h$ as defined by

$$
q(t)=h(t) \Delta T(t)
$$

where $q$ is the heat flux and $\Delta T$ is a thermal potential for driving the heat flux, and all terms vary as functions of time through the cycle. For steady pipe flow $\Delta T$ is typically taken as the difference between the bulk fluid temperature, $T_{\mathrm{B}}$, and the wall temperature. $T_{\text {wall }}\left(\Delta T=T_{\mathrm{B}}-T_{\text {wall }}\right)$. The bulk temperature is an energy-weighted average of the fluid temperature across the pipe, with a typical definition being

$$
T_{\mathrm{B}}=\frac{\int_{A} \rho U(A) C_{p} T(A) \mathrm{d} A}{\int_{A} \rho U(A) C_{p} \mathrm{~d} A},
$$

where $C_{n}$ is the constant-pressure specific heat, $p$ is the density, and $A$ is the cross-sectional area of the pipe. However, this definition is ambiguous when applied on a cycle-resolved basis to the oscillating flow in the pulse combustor tail pipe. As the flow reverses, the cycle-resolved velocity goes through zero twice each cycle, causing anomalies in a cycle-resolved bulk temperature based on equation (5). Hence, an alternative to this classically defined bulk temperature is required to determine a thermal potential $\Delta T$.

Various alternatives to the classic $\Delta T$ using the bulk temperature were considered. These included a spatially averaged temperature with a steady (non-cyclic) weighting function such as the cycle-averaged velocity or mass flow profile, a centerline temperature, and a spatially averaged temperature across the core. The first of these alternatives, like the bulk temperature, provides an average over the entire flow cross-section, but unlike the steady flow bulk temperature, does not have a physical significance. The centerline temperature is the simplest alternative, but it relies on the accuracy of a single experimental data point. The third 
alternative, forming a spatial average across the core, was selected for this study. Examination of the temperature profiles across the $30 \mathrm{~mm}$ square tail pipe given in ref. [15] shows that the temperature is almost uniform across the flow except for a $3-5 \mathrm{~mm}$ boundary layer region. The temperature difference between this uniform core region and the wall provides the thermal potential for driving the heat transfer to the wall. Accordingly, an average core temperature provides a logical alternative to the bulk temperature in determining the thermal potential $\Delta T$ is equation (4). The ensemble-averaged cycle-resolved core temperature, $\left\langle T_{\text {core }}\right\rangle$, was determined by a simple area-weighted average of the $\langle T\rangle$ data from the centerline to within $5 \mathrm{~mm}$ of the wall. This limit to the average was selected as being the minimum extent of the uniform-temperature region through the cycle, although varying the limit of the average by $\pm 1.5 \mathrm{~mm}$ had little effect on the results. Using this $T_{\text {core }}$ to define $\Delta T(\Delta T=$ $T_{\text {corc }}-T_{\text {wall }}$ ) in equation (4) fixes the definition of $h$ used here. Finally, it should be noted that because the temperature is almost uniform across the majority of the cross-scction, whether this core temperature or onc of the other alternatives suggested above is used, the differences in the values of $h$ computed using equation (4) are small, and it does not affect the conclusions.

$\left\langle T_{\text {corc }}\right\rangle$ for the base condition is shown in the top plot of Fig. 7. Comparison with Fig. 4 shows the similarity of $\left\langle T_{\text {core }}\right\rangle$ with $\langle T\rangle$ at the centerline. The ensemble-averaged wall heat flux corresponding to this location is shown in the center plot. Also shown in Fig. 7 are the first harmonics (obtained by a Fourier series decomposition) of the curves. It may be seen

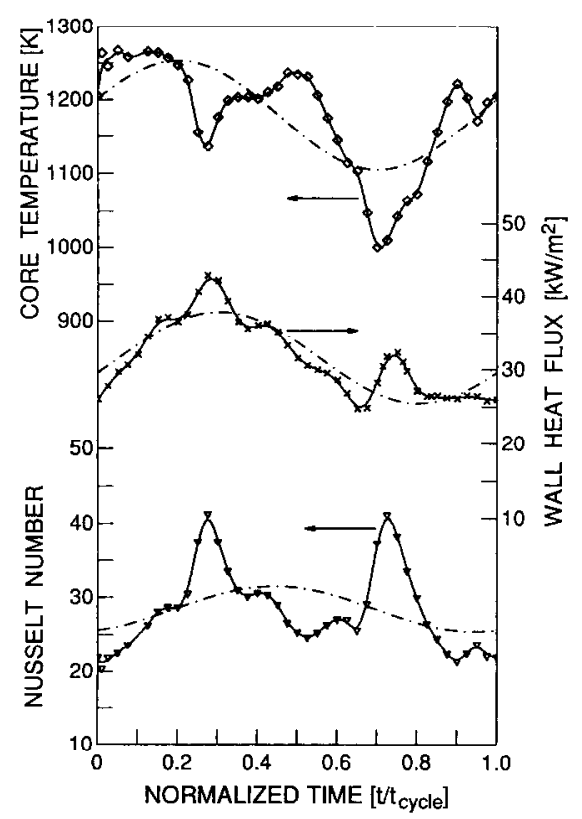

FIG. 7. Time-resolved bulk-averaged gas temperature, heat flux, and Nusselt number at the base operating condition and location. that the fundamental oscillations of the core temperature and heat flux are in-phase, indicating that the fundamental oscillation in the heat flux is caused by the temperature oscillation rather than a convective transport oscillation. At the zero-velocity crossings (times 0.25 and 0.7 ), however, the temperature drops and the heat flux increases, indicating that an increase in the convective transport occurs at these cycle times.

Shown in the bottom plot of Fig. 7 are the cycleresolved Nusselt numbers, which were calculated from equation (4) using these $\left\langle T_{\text {core }}\right\rangle$ and heat flux data, and the wall temperature obtained with the thin film thermocouple. The value of $k$ for the Nusselt number was taken to be that of a mixture of $\mathrm{N}_{2}, \mathrm{CO}_{2}$, and $\mathrm{H}_{2} \mathrm{O}$ resulting from complete combustion of the reactants. As anticipated from the above discussion, the Nusselt number is nearly constant through the cycle, with the exception of local increases at times 0.25 and 0.7 , the zero-velocity crossings. For steady turbulent flow at this mean Reynolds number, a Nusselt number of 15 is predicted by the Colburn correlation. The background level of the Nusselt number in this oscillating flow is about a factor of two greater, and at the zero-velocity crossings it is a factor of three greater. Thus, the rate of convective transport is improved at all cycle times but additional transport is generated during the zero-velocity crossings. Examination of these local increases shows that the additional transport is generated very rapidly and decays more slowly (note that all data points are at equal time intervals). The beginning of the rise coincides temporally with the flow reversal at the wall which slightly phaseleads that of the core [10]. These locally high rates of convection are thought to result from transverse flows gencrated by the reversal process, although the mechanisms are not understood. This phenomenon is discussed further in the next subsection.

\section{Anomalies at times of flow reversal}

The temperature and heat flux data presented in Fig. 7 suggest that there are three-dimensional effects in this flow. $\left\langle T_{\text {corc }}\right\rangle$ was obtained by integrating the temperature along a $Y$ profile at $Z=0$. The dips in $\left\langle T_{\text {corc }}\right\rangle$ at times 0.25 and 0.7 show that along this profile the gas temperature drops then increases again, as the velocity reverses. The gas temperature drop is thought to result from heat transfer to the wall, since the wall heat flux increases nearly simultaneously; however, the subsequent temperature rise is not readily explained. As seen in the second plot in Fig. 7, the wall heat flux is always positive, i.e. out of the exhaust gases, so it cannot cause the temperature increase. $\langle T\rangle$-time histories at several axial locations showed that these dips occur simultaneously everywhere along the tail pipe [15], so axial convection can only bring fluid to the probe volume which has also undergone a temperature drop. Three-dimensional effects are the only remaining alternative. If the gas at another $Z$ location does not undergo an energy loss at these cycle times, this hotter gas could mix with the gas at $Z=0$ 
(the profile location), which loses energy, causing the temperature to rise. This effect requires that there be some flows in the transverse $(Y-Z)$ plane at times of flow reversal. The transverse flows could take the form of secondary flows, which have the same velocity and occur at the same transverse location with the same orientation each reversal, or they could take the form of coherent vortex structures, which occur at random locations and orientations each cycle. The term 'transverse flow' will be used to collectively refer to these two possible phenomena. It should be noted that the tail pipe used in this study had a square cross-section which will cause secondary flows, and these secondary flows may have some effect on the transverse flows discussed above.

Additional evidence of a strong transverse flow at the zero-velocity crossings is found in the relative density of the atomic indium seed used for the TLAF temperature technique. Although the TLAF temperatures are independent of the seed concentration [20], the seed density may be calculated from the intensity of the fluorescence of one fluorescence line and the temperature, within a constant. Seed density-time histories for various $Y$ positions are shown in Fig. 8. $\langle T\rangle$-time histories are also shown for reference. The highest seed densities and temperatures are at the centerline location with the lowest near the wall. Although the reason for the low concentrations of the atomic indium seed near the wall is not known, it provides a marker for the fluid. Figure 8 shows that the seed density, like $\langle T\rangle$, drops during the times of flow reversal, then rises again. This same behavior was seen at all axial locations, except near the contraction section. Assuming that the low seed concentration marks fluid which has recently come from near the wall, the same arguments made in the above dis-
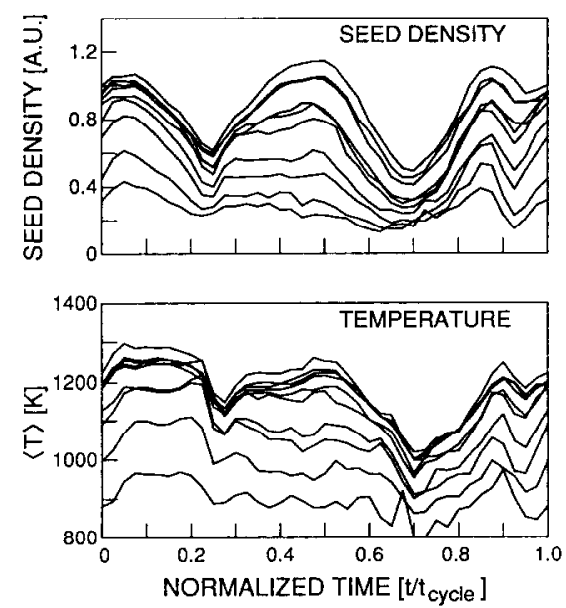

FIG. 8. Atomic indium seed density and temperature fluctuations through the cycle at various $Y$ locations. The curves showing higher seed densities and temperatures are from the core region with the lower valued curves being from the boundary layer region. Base operating condition and location. cussion of the temperature may be applied to support the existence of three-dimensional effects in this flow.

There is also evidence to suggest that these phenomena observed during the flow reversals are related to the Nusselt number enhancement in oscillating flows. As discussed previously, the magnitude of the second harmonic of the temperature-time history is a measure of the magnitude of the temperature dips at the times of flow reversal. In a previous work, Dec and Keller [15] presented profiles of the amplitude of this harmonic and noted a trend of increasing amplitude with frequency. The Nusselt number also increases with frequency [7], suggesting that a relationship exists between the temperature dips at the zero-velocity crossing and the Nusselt number enhancement. In Fig. 9 the amplitude of the second harmonic of the core temperature and the time-averaged Nusselt number enhancement at the same axial location and operating condition are shown as functions of frequency. (Based on scatter in the heat flux data, which resulted from small variations in the set-up of the modular tail pipe, the uncertainty of these Nusselt number enhancements is estimated to be $\pm 12 \%$.) In the figure, similar trends can be seen for the 67,74 and $83 \mathrm{~Hz}$ data at the $X=540 \mathrm{~mm}$ location. The reverse trend for the 83 and $101 \mathrm{H} \angle$ cases at the $X=340 \mathrm{~mm}$ location is thought to be due to noise in the locally measured heat flux data, since the Nusselt numbers for 83 and $101 \mathrm{~Hz}$ averaged over the entire tail pipe [7] show a modest Nusselt number increase with frequency. Note that the second harmonic amplitude is rapidly getting smaller at the lower frequencies studied, which suggests that transverse flows may not be present at low frcquencics. An enhancement in the Nusselt number also occurs with increases in pulsation amplitude, and a decrease in the enhancement occurs with increased mean flow rate, when the other parameters are held constant [7]. Insufficient data were obtained to determine whether the second harmonic

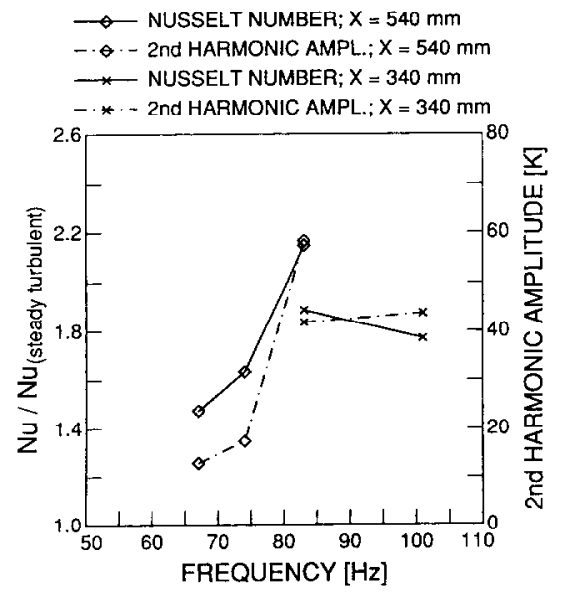

FIG. 9. Comparison of the frequency dependence of the timeaveraged Nusselt number and the second harmonic of the cyclic fluctuations of the bulk temperature. 
Table 1. Variations in the time-averaged Nusselt number and the second harmonic of the cyclic fluctuations of the buik temperature; shown are two pulsation amplitudes at the same frequency and mean Reynolds number, and two mean Reynolds numbers

\begin{tabular}{ccccc}
\hline$R e$ & $\begin{array}{c}\text { Frequency } \\
{[\mathrm{Hz}]}\end{array}$ & $\begin{array}{c}P_{\mathrm{RMS}} \\
{[\mathrm{kPa}]}\end{array}$ & $\begin{array}{c}\left\langle T_{\text {core }}\right\rangle \\
\text { Second harmonic } \\
\text { amplitude } \\
{[\mathrm{K}]}\end{array}$ & $\begin{array}{c}\text { Nusselt } \\
\text { number }\end{array}$ \\
\hline 3800 & 74 & 7.3 & 17.5 & 25.0 \\
3800 & 74 & 8.4 & 22.4 & 26.9 \\
3750 & 83 & 7.4 & 58.3 & 32.9 \\
4400 & 90 & 8.6 & 38.4 & 29.1 \\
\hline
\end{tabular}

amplitude of $\left\langle T_{\text {core }}\right\rangle$ could also be related to these Nusselt effects, although the data in Table 1 hint that there may be a relation.

Although Fig. 9 shows a relationship between the Nusselt number and magnitude of the temperature dips, the increased convection at times of flow reversal alone may not be sufficient to explain the large Nusselt number enhancements in oscillating flows. Integration of the Nusselt number curve in Fig. 7 shows that the areas of the "spikes" that occur at the times of flow reversal constitute only about $15 \%$ of the total Nusselt number enhancement. Either the fluid mechanics which create these spikes also add to the general turbulence intensity through the remainder of the cycle, or there is another mechanism contributing to the heat transfer enhancement. Thus, the heat transfer enhancement may arise from two distinct sources, as discussed in the next section.

\section{HEAT TRANSFER ENHANCEMENT MECHANISMS}

The mechanisms responsible for the heat transfer enhancement in reversing, oscillating turbulent flows are not known. Several hypotheses have been suggested in the literature, and to the authors in verbal discussions. In this section, these hypotheses and their relative merits, in view of the authors' recent studies, are discussed. In addition, some new hypotheses, which the authors feel are suggested by their data, are presented and discussed.

\section{Transition to fully turbulent conditions}

Some authors have studied the effects of oscillations on flows that were not fully turbulent under steady conditions. They noted that oscillations would cause these flows to become fully turbulent at lower mean Keynolds numbers than if the flow were steady $[1,22]$. Miller [1] concludes that some increased heat transfer coefficients reported in the literature are due simply to "early transition and not of alteration of the local heat-transfer coefficient'. Although this may be the case if oscillations are much smaller than the mean flow, when the oscillation amplitude is sufficient to create strong flow reversals, significant enhancements relative to steady, fully turbulent flow have been found $[4,5]$. Similar results were found in the pulse combustor tail pipe used in this study. Steady flow in the tail pipe was not fully turbulent [10], and the steady flow Nusselt numbers were between those expected for laminar and turbulent flows [7]. Compared to these values, the oscillations enhanced the Nusselt number by a factor of 3 or 4 , while the enhancement factor relative to fully turbulent flow was $2-2.5$. Thus, although the oscillations do induce a transition to fully turbulent flow, this mechanism does not explain why the Nusselt number is enhanced well beyond the expected value for fully turbulent flow.

\section{Acoustic streaming}

Flow oscillations that vary in amplitude with axial position, as acoustically resonant flows do, generate a secondary time-averaged velocity component. This phenomenon, commonly called 'acoustic streaming', has been suggested as a mechanism for Nusselt number enhancement in oscillating flows [23]. For pipe flow, the flows generated by acoustic streaming have the form of large longitudinal recirculation cells that are one quarter the length of the acoustic wavelength and occur at half-wavelength intervals [23]. In the quarter wavelength between these cells, acoustic streaming causes a velocity component towards the wall of the pipe, increasing the velocity near the wall $[23,24]$. The pulse combustor resonates as a quarterwave tube, but the quarter wavelength coincides with the acoustic streaming pattern of the recirculation cells, not the flow toward the wall. If this secondary flow were evident in the tail pipe the mean velocity profiles would show a reversal, with the mean velocity near the wall being negative. No evidence of this secondary flow is seen in the time-averaged velocity profiles (Fig. 5 and ref. [10]). This is not surprising since the tail pipe itself constitutes only part of the quarter wavelength, and the velocity oscillation amplitude varies little from inlet to exit (Fig. 1 and ref. [10]). Although these flows may have some effect on the mean heat transfer in pipes which are several wavelengths long, the effect in the wavelength fraction of the pulse combustor tail pipe might actually decrease the Nusselt number. It can be concluded that the effects of acoustic streaming are small in the pulse combustor tail pipe and are not important in the observed Nusselt number enhancement.

\section{Entrance effects}

It is well known that Nusselt numbers are higher in the entrance regions of pipes due to the thin, undeveloped thermal boundary layer. In a reversing oscillating flow these effects can occur at both the entrance and exit, although not simultaneously at both locations. Since the tail pipe lengths used in this study, and in other pulse combustors, range from 23 to 56 diameters in length, it is possible that entrance effects play a role in the observed enhancement. Axially resolved measurements of the Nusselt number in the 
tail pipe used in this study [7] showed little change with axial position except for the test location nearest the exit. Similar results were found by Reay [25] in another pulse combustor tail pipe. These Nusselt number measurements are supported by axially resolved measurements of the velocity and temperature boundary layers in this tail pipe $[10,15]$. The velocity profiles showed a small variation at the entrance and larger variation at the exit (attributed to the gradual contraction at the entrance and the sharpedged exit), but no change with axial location in the center of the pipe. The normalized temperature profiles at the entrance and center were all virtually identical, in agreement with the Nusselt number data. These velocity and temperature profiles, as well as the Nusselt number measurements, show that entrance effects are not important in the central region of the tail pipe, where the Nusselt number enhancement over fully turbulent flow was a factor of 2 for the base condition (Fig. 9). The increased Nusselt number at the exit was found to increase the axial-averaged Nusselt number by about $17 \%$ for the base condition. This percentage increase is in general agreement with typical correlations for steady turbulent pipe flow, which show entrance effects to increase the Nusselt number by $25-30 \%$ for the length-to-diameter ratios used in this study. It can be concluded that the entrance effects add to the observed heat transfer increase for the entire tail pipe, and may partially contribute to the observed increase with frequency since shorter tail pipes were used for the higher frequencies. However, their contribution is not sufficient to explain the observed enhancements over the rates expected for steady turbulent flow, or the observed increase with frequency.

\section{Stripping of the boundary layer}

It has been speculated, both in the literature [26] and verbally, that flow oscillations periodically 'break down' or 'strip' the thermal boundary layer. Under this hypothesis, this stripping prevents the boundary layer from becoming developed, causing entrance-like conditions throughout the tail pipe. The time-resolved thermal boundary layers measured in this flow and presented in ref. [15] clearly show that this is not the case. The boundary layer was found to be well developed throughout the cycle; moreover, the cyclic fluctuations in the boundary layer thickness do not correspond with increases in the heat flux or Nusselt number.

\section{Quasi-steady flow}

Some previous studies have found their results to correlate with quasi-steady Nusselt number predictions $[3,5,22,27]$. This hypothesis assumes that at any point in time during the cycle, the flow behaves as if it were steady at the instantaneous absolute value of the velocity. Thus, the heat transfer enhancement arises because on average the absolute value of the velocity is much higher than the mean velocity. For this assumption to be valid, the time scales for the velocity and thermal profiles to come to equilibrium must be much shorter than the oscillation time scales (see refs. [7, 22] for discussions). The time-resolved velocity profiles presented in ref. [10] clearly show that this assumption is not valid for the frequencies in this study $(67-101 \mathrm{~Hz})$. Typically the quasi-stcady hypothesis is applied to heat transfer by using steady flow Nusselt number correlations in a quasi-steady manner. This implies the further assumption that steady flow Nusselt number correlations, which are based on the Reynolds analogy between momentum and energy, are valid in the oscillating flow. As discussed previously, and in ref. [15], the Reynolds analogy is not valid in this type of reversing oscillating flow. Also, these steady flow Nusselt number correlations have been developed for flows that have favorable pressure gradients, unlike the resonant flow in the tail pipe, in which the pressure gradient varies from favorable to adverse through the cycle. Finally, the Nusselt number enhancement has been shown to be a function of the oscillation frequency [7], and the quasi-steady hypothesis predicts no effect of frequency.

\section{Increased turbulence intensity}

It is well known that increases in turbulence intensity increase convective heat transfer rates. In an oscillating flow in which $U_{\text {o:c }}$ is much larger than $U$, the average rate of shear in the boundary layer can be as great as that of a steady flow at a much higher velocity. Since velocity shear laycrs can produce turbulent velocity fluctuations, it is reasonable to expect increased turbulence levels in strongly oscillating flows. Both the streamwise and transverse components of the turbulence intensity, for a range of operating conditions, are presented and discussed in ref. [10]. These data (see also Fig. 6) show that in the oscillating flow, the turbulence intensity of both velocity components is much higher than that of steady flow. Neither component of the turbulence intensity was found to vary consistently with the frequency. This is reasonable if the dominant producer of turbulence is boundary layer shear, since the average velocity shear in an oscillating flow is a function of the magnitudes of $U_{\text {ose }}$ and $U$ and is independent of frequency. Indications of an increase in turbulence with pulsation magnitude were found; however, the range of pulsation amplitude was insufficient to assure that this trend is definitive.

The turbulence intensity is believed to be the main mechanism for momentum transport in this oscillating flow, but is insufficient to explain all the observed heat transfer trends. Time-averages of both the wall shear stress and the absolute value of the wall shear stress, which are measures of the momentum transport, were found to increase with pulsation magnitude, but to have no variation with frequency [10] (see also Fig. 5), as does the turbulence intensity. Unlike the wall shear stress, the Nusselt number is also a function of oscillation frequency [7]. The increased 
turbulence intensity undoubtedly contributes to the Nusselt number enhancement; however, there must be another contributor, which increases the heat transfer with frequency, but does not affect the wall shear stress.

\section{Additional convection at times of flow reversal}

High convective rates at times of flow reversal would provide a mechanism for transporting thermal energy but not momentum. When the flow is reversing, the velocity is near zero across the entire crosssection of the tail pipe, as may be seen in the timeresolved profiles presented in ref. [10]. Thus, there is no momentum in the core region to transport to the region near the wall. In contrast, the gas temperature in the core is always much higher than the wall temperature [15], so convective transport at times of flow reversal will contribute to the time-averaged Nusselt number.

In the discussion of the data in the previous section, it was noted that there are several pieces of evidence that suggest increased convection at times of flow reversal. Furthermore, the magnitude of the added convection at the zero-velocity crossings appears to increase with frequency in a manner similar to the time-averaged Nusselt number increase (Fig. 9), which could explain the frequency dependence of the temperature profiles and Nusselt numbers that is not seen in the velocity profiles and shear stresses. Since this additional convective transport and the ordinary turbulence both transport thermal energy, but not momentum, at the times of flow reversal, the reason for the time-averaged temperature profile being flatter across the core than that of the velocity (Fig. 5) is also explained. A combination of increased shear-layer gencrated turbulence and strong convection at the zero-velocity crossings by transverse flows is thought to provide the best explanation for the mechanisms causing the observed heat transfer enhancement. However, the fluid mechanics responsible for the additional convective transport during the flow reversal are not currently understood.

\section{SUMMARY AND CONCLUSIONS}

Convective heat transfer rates in oscillating turbulent flows, in which the oscillations are sufficiently strong to cause flow reversal, have been found to be much higher than those in steady turbulent flow. In order to clucidate the mechanisms of the enhanecment, the temperature and velocity fields were compared and the cyclic behavior of the Nusselt number calculated and discussed.

Time-averaged temperature and velocity profiles at different oscillation frequencies were compared and discussed. Also, time-averaged streamwise turbulence intensity profiles were compared with the time-averaged profiles of the random temperature fluctuations and the differences discussed. Time-averaged temperature profiles were found to show an increase in the temperature gradient at the wall with frequency, while the velocity profiles at the same two frequencies showed virtually identical wall gradients. This is in agreement with previous Nusselt number and wall shear stress behavior $[7,10]$. These results indicate that thermal energy in these oscillating flows is transported by a frequency-dependent flow to a much greater extent than is momentum.

Time-resolved Nusselt numbers were calculated from time-resolved gas temperatures and timeresolved heat flux data. The Nusselt number was found to be nearly constant over most of the cycle with large increases twice each cycle, at times of flow reversal, At all cycle times the gas temperature is much higher than the wall temperature, while during flow reversal the velocity is near zero across the tail pipe. As a result, convection at times of flow reversal transports thermal energy, but not momentum. The amplitude of the second harmonic of the cyclic temperature fluctuations, which is associated with this increased convection at times of flow reversal, was found to increase with the oscillation frequency, as was the time-averaged Nusselt number, suggesting a relationship between these phenomena. This transport suggests a possible explanation why frequency effects in the temperature profiles and Nusselt number are not seen in the velocity profiles and wall shear stress.

Possible causes for the heat transfer enhancement in oscillating flows were reviewed and discussed. Examination of the heat transfer data in the literature, recent detailed time-resolved studies of the velocity and temperature fields $[10,15]$, and the data presented in this paper, do not support most of the hypotheses. The data suggest that the heat transfer enhancement is most likely caused by a combination of increased turbulence intensity and strong transverse flows generated during the streamwise velocity reversals.

Acknowledgements The authors would like to express their gratitude to I. Hongo of Toshiba Corporation for his assistance in the data acquisition and to P. K. Barr of Sandia for her preparation of Fig. 1. This work was performed at the Combustion Research Facility at Sandia National Laboratories and was supported by the U.S. Department of Energy, Advanced Industrial Concepts Program (formerly Energy Conversion and Utilization Technologies Program) and the Gas Research Institute.

\section{REFERENCES}

1. J. A. Miller, Heat transfer in the oscillating turbulent boundary layer, ASME I. Engng Pur 239-244 (October 1969).

2. N. S. Liao, C. C. Wang and J. T. Hong, An investigation of heat transfer in pulsating turbulent pipe fow, $A S M E$ $23 r d$ Natn. Heat Transfer Conf., Fundamentals of Forced and Mixed Convection (Edited by F. A. Kulacki and R. D. Boyd), HTD-Vol. 42 (1985).

3. J. S. Park, M. F. Taylor and D. M. McEligot. Heat transfer to pulsating, turbulent gas flow, Seventh Int. Heat Transfer Conf., Heat Transfer 1982, Vol. 3 (1982).

4. R. H. Keil and M. H. 1. Baird, Enhancement of heat transfer by flow pulsation, Ind. Engng Chem. Process Des. Dev. 10, 473 (1971). 
5. V. I. Hanby, Convective heat transfer in a gas-fired pulsating combustor, ASMEJ. Engng Pwr 91, 48 52 (1969).

6. B. M. Galitseyskiy and Yu. A. Ryzhov, Heat transfer in turbulent gas flows in the case of high-frequency pressure fluctuations, Heat Transfer-Soviet Res. 9, 178-183 (1977).

7. J. E. Dec and J. O. Keller, Pulse combustor tail-pipe heat-transfer dependence on frequency, amplitude, and mean flow rate, Combust. Flame 77, 359-374 (1989).

8. W. N. Zartman and S. W. Churchill, Heat transfer from acoustically resonating gas flames in a cylindrical burner. A.I.Ch.E. Jl 7, 588-592 (1961)

9. E. H. Perry and F. E. C. Culick, Measurements of wall heat transfer in the presence of large-amplitude combustion-driven oscillations, Combust, Sci. Technol. 9, 49-53 (1974).

10. J. E. Dec, J. O. Keller and I. Hongo, Time-resolved velocities and turbulence in the oscillating flow of a pulse combustor tail pipe, Combust. Flame 83, 271-292 (1991). Also Sandia National Laboratories Report, SAND888844.

11. A. A. Putnam, F. E. Belles and J. A. C. Kentfield, Pulse combustion, Prog. Energy Combust. Sci. 12, 43-79 (1986).

12. B. T. Zinn, State of the art and research needs of pulsating combustion, ASME Winter Annul Meeting. ASMF Paper 84-WA/NCA-19 (Dec. 1984).

13. Proceedings, Vol. I: Symposium on Pulse Comhustion Applications, GRI-82/0009.2. Gas Research Institute, Chicago, Illinois (1982).

14. J. O. Keller and 1. Hongo, Pulse combustion: the mechanisms of $\mathrm{NO}_{x}$ production, Combust. Flame 80, 219-237 (1990).

15. J. E. Dec and J. O. Keller. Time-resolved gas temperatures in the oscillating turbulent flow of a pulse combustor tail pipe, Combust, Flame 80, 358 - 370 (1990).

16. J. E. Dec and J. O. Keller, The ellect of fuel burn rate on pulse combustor tail pipe velocities, Proc, Int. Gas Reseuroh Conf., Vol. 2, pp. 22 31. Gas Research Institute, Chicago, llinois (September 1986). Also report SAND86-8757, Sandia National Laboratories, Livermore. California (1986).

17. J. O. Keller, I. E. Dec, C. K. Westbrook and T. T. Bramlette, Pulse combustion: the importance of characteristic times, Combust. Flame 75, 33.44 (1989).

18. J. O. Keller, C. K. Westbrook, T. T. Bramlette and J. E Dec. Pulse combustion: the quantification of characteristic times. Combust. Flame 79, $151 \quad 161$ (1989).

19. T. T. Bramlette. The role of fluid dynamic mixing in pulse combustors, SAND87-8622, Sandia National Laboratories, Livermore, California (1987).

20. J. E. Dec and J. O. Keller, High speed thermometry using two-line atomic fluorescence. Twenty-first Symp. (InI.) on Combustion, pp. 1737-1745. The Combustion Institute (1986).

21. H. Schlichting. Bowndary Layer Thery (6th Edn), pp 532 and 563.565 . McGraw-Hill, New York (1968)

22. R. Lemlich. Vibration and pulsation boost heat transfer, Chem. Enong 68, 171-176 (1961).

23. T. W. Jackson and K. R. Purdy, Resonant pulsating flow and convective heat transfer, ASME J. Heat Transfer 507-512 (November 1965).

24. K. R. Purdy, T. W. Jackson and C. W. Gorton, Viscous fluid flow under the influence of a resonant acoustic field, ASME J. Heat Transfer 97-106 (February 1964).

25. D. Reay, The thermal efficiency, silencing, and practicability of gas-fired industrial pulsating combustors, $J$. Itist. Fuet 22, 135 142 (1969).

26. P. C. Lalwani, K. L. Das, T. K. Bhatacharyya and D. Bhaduri, Heat transfer characteristics of a pulsating combustion system, Mech. Engng Bull. 10, 7-10 (March/June 1979).

27. J. C. Ludlow, D. J. Kirwan and J. L. Gainer, Heat transfer with pulsating flow, Chem. Engng Commun. 7 , $211.218(1980)$

\section{APPENDIX}

The cycle-resolved heat flux was obtained from the wall thermocouples by solving the transient conduction equation in the wall. The linearity of the thermal energy equation in the wall allows it to be separated into mean and transient components. This was particularly advantageous for the pulse combustor tail pipe, since the mean wall temperature was high $(\sim 800 \mathrm{~K})$, while the surface temperature oscillated only about $0.56 \mathrm{~K}$. Two readings of the thin-film thermocouple (located on the inner wall surface) were taken. First. a long-time average (an average over the entire cycle of many combustor cycles) at a low amplification provided the mean surface temperature. Second, at a higher amplification the a.c. component of the thermocouple signal was ensembleaveraged over a minimum of 400 combustor cycles. This higher amplification and ensemble averaging permitted the small oscillating signal to be accurately determined.

The mean heat flux was calculated from the mean surface temperature (obtained from the thin-film thermocouple) and the mean temperature of the second thermocouple, which was embedded at a known distance $(\approx 2 \mathrm{~mm})$ below the surface, using the known conductivity of fused silica quartz at the appropriate temperature.

The fluctuating component of the heat flux was calculated from the ensemble-averaged surface temperature fluctuations. It was not necessary to know the fluctuating component of the temperature of the embedded thermocouple, since calculations showed that surface temperature oscillations, at the frequencies of interest, would be attenuated to $1 \%$ of their surface values in a distance much less than the $2 \mathrm{~mm}$ which separated the two thermocouples. This allowed the transient part of the energy equation to be treated as a penetration into a semi-inifinite solid. The heat flux solution for a semi-infinite solid with a sinusoidally oscillating surface temperature is well known. Since the surface temperature fluctuations were not sinusoidal, a Fourier series decomposition of the ensemble-averaged temperature was performed. The first 10 harmonics were found to be sufficient to reproduce the temperature fluctuations, and for each of these 10 harmonics the oscillating heat flux into the semiinfinite solid was calculated. These individual frequency components of the heat flux were then summed and added to the mean heat fux to get the total heat Iux shown in Fig. 7.

\section{ACCRUISSEMENT DU TRANSFERT THERMIQUE PAR L'ECOULEMENT TURBULENT OSCILLANT DANS LE TUBE D'UN COMBUSTEUR PULSE}

Résumé-Les transferts thermiques dans les tubes de queue des combusteurs pulsés et dans les autres écoulements turbulents, oscillants avec retour, sont plus élevés que ceux relatifs à un écoulement turbulent permanent. Pour comprendre les mécanismes de cet accroissement, les champs de température et vitesse sont comparés a partir des mesures de fluorescence atomique à deux lignes (TLAF) et de velocimétrie laser Doppler (LDV), respectivement. On présente el discute les flux thermiques pariétaux instantanés el les nombres de Nusselt. Les causes possibles de laccroissement de transfert thermique dans les ćcoulements oscillants sont passées en revue et discutées à partir des résultats expérimentaux présentés et des publications antérieures. 


\section{VERRESSERUNG DES WÄRMEÜBERGANGS IN DER OSZILLIERENDEN TURBULENTEN STRÖMUNG EINES PULSIERENDEN NACHBRENNERS}

Zusammenfassung-Es wurde festgestellt, daß die Wärmeströme in einem pulsierenden Nachbrenner und in anderen oszillierenden turbulenten Strömungen wesentlich größer sind als bei stationären turbulenten Strömungen. Um den Vorgang der Verbesserung zu verdeutlichen, werden die Temperatur- und Geschwindigkeitsfelder mit einem Zweilinien-Atom-Fluoreszenz-Verfahren und mit Laser-Doppler-Anemometrie gemessen und miteinander verglichen. Es wird der zeitliche Verlauf der Wärmestromdichte an der Wand und der Nusselt-Zahl dargestellt und diskutiert. Mögliche Gründe für die Verbesserung des Wärmeübergangs in oszillierenden Strömungen werden genannt und erläutert in Bezug auf die hier dargestellten Ergebnisse und die neueste Literatur.

\section{ИНТЕНСИФИКАЦИЯ ТЕПЛОПЕРЕНОСА ПРИ КОЛЕБАТЕЛЬНОМ ТУРБУЛЕНТНОМ ТЕЧЕНИИ В ВЫХЛОПНОЙ ТРУБЕ ИМПУЛЬСНОЙ КАМЕРЫ СГОРАНИЯ}

Аннотацня-Найдено, что скорости теплопереноса в выхлопных трубах импульсной камеры сгорания и при других возвратных колебательных турбулентных течениях значительно выше, чем при установившемся турбулентном течении. С целью объяснения механизмов интенсификации теплопереноса проводится сравнение полей температур и скоростей, найденных с использованием соответственно атомной флуоресценции (TLAF) и лазер-допплеровского метода измерения скорости (DLV). Приводятся также тепловые потоки на стенке и числа Нуссельта. Описываются и обсуждаются возможные причины интенсификации теплопереноса при колебательных течениях с учетом данных, представленных в настоящем исследовании и в современной литературе. 